\title{
Non-stationarity driven by long-term change in catchment storage: possibilities and implications
}

\author{
J. D. Hughes and J. Vaze \\ CSIRO Land and Water, Canberra, ACT, Australia \\ Correspondence to: J. Hughes (justin.hughes@csiro.au)
}

Received: 11 March 2015 - Accepted: 11 March 2015 - Published: 12 June 2015

\begin{abstract}
Non-stationarity" with reference to hydrology is a term applied to many situations (Milly et al., 2008). While climate change non-stationarity is often examined, these effects can provide a test for assumptions of runoff generation process impliedin rainfall-runoff (RR) models.

Observations from South-western Australia (SWA) over the past 40 years show a decline in rainfall and reductions in runoff. Runoff and rainfall relationships in SWA show a significant shift over the past 40 years suggesting a change in runoff generation and catchment state. This has challenged the nature of assumed runoff generation process in SWA as well as the veracity of conceptual RR model structure.

We expand on some of the lessons learned from SWA and discuss the climatic and geomorphic conditions that may make reasonable predictions of runoff very difficult with RR models calibrated in traditional ways. Catchment storage has a significant interaction with runoff generation and we examine the situations where these may change in the longer term. We suggest some strategies in terms of model structure and calibration that may improve predictive performance in such situations.
\end{abstract}

\section{Introduction}

The field of hydrology is dominated by the interplay between observation and the representation of processes in predictive models. Models are required since it is not practical to measure hydrological variables at temporal and spatial scales required for resource management. Also, models allow investigation of "what-if" scenarios that are not available via direct observation and will remain vital to water resource management.

There are variation and subtleties in hydrological models with regards to their intended use, strengths and weaknesses, and what perceived hydrological processes they may mimic. Among these subtleties it is easy to become distanced from what a hydrological model really represents. This is true even when more focussed on rainfall-runoff (RR) models.

The perceptual model (Beven, 2012) is a hydrologist's estimate of the basic "plumbing" of catchment hydrology from a context of interest, and is somewhat subjective, but is based upon experience and observation. The process of hypothesis testing, and model improvement follows an iterative loop that continually tests and updates process understanding and the perceptual model used on which any simulation code may be based against any available data. Despite calls to have "experimentalists" work more closely with "modellers" (Klemes, 1986; Silberstein, 2006), this has rarely been observed.

Observations in South-western Australia (SWA) have provided a unique opportunity to test and update the perceptual model that is the basis of rainfall runoff models. Changing conditions and catchment hydrological response has prompted a rethink in the perceptual model with ramifications for any simulation code. We examine some of these changes and suggest environments where similar observations are possible. We examine a "perceptual" flaw in many RR models and suggest a possible update to model structure.

\section{South-western Australia - a changing perceptual model}

SWA in the context of this manuscript refers to the south-western corner of Western Australia, dominated by a Mediterranean climate. The area of interest is predominately 
forested, and includes the main water catchment for the Perth metropolitan areas (see Hughes et al., 2012). The regolith of the area is deep $(\sim 40 \mathrm{~m})$ and is very transmissive. Annual rainfall in the area varies between 900 and $1300 \mathrm{~mm}$, while annual potential evaporation is $1200-1400 \mathrm{~mm}$. The SWA has experienced a drying trend since the mid 1970's, although this has been described as more of a step change than gradual drying (IOCI, 2002). Rainfall had declined by 15-20\% since the 1970's with a concurrent reduction in runoff of greater than $70 \%$ (Bates et al., 2008). Petrone et al. (2010) showed that runoff fell dramatically following droughts within the 1988-2009 time period, although no significant trend in rainfall could be indentified throughout this period. This trend in declining runoff has continued with a major drought in 2010.

Runoff generation in SWA was thought to be dominated by throughflow from ephemeral, perched aquifers that form in the sandy gravel topsoil above layers of lateritic duricrust, or less permeable subsoil. This is despite subsequent investigations that indicate the local lateritic duricrust being of high permeability (Ruprecht and Schofield, 1993). The role of deeper groundwater (formed above the bedrock) was thought to be relatively unimportant in the generation of runoff (Stokes and Loh, 1982; Stokes, 1985; Turner et al., 1987; Williamson et al., 1987). Again this differs from the view of Ruprecht and Schofield (1989), who proposed permanent groundwater as being critical in runoff generation. It should be noted that most of these studies were conducted during "wetter times". Infiltration-excess runoff is considered less likely due to the permeable nature of the regolith.

Petrone et al. (2010) noted a changing runoff-rainfall $(Q \sim P)$ relationship across various SWA catchments during the post-1970 period. An update of their plot is shown below for a selection of catchments (Fig. 1). These relationships show that a single $Q \sim P$ relationship is inadequate, and this could be interpreted as a type of "non-stationarity". Obvious changes in the relationship follow drought years 2001 and 2010. More recent analysis (Hughes et al., 2012; Kinal and Stoneman, 2012) show that permanent groundwater plays a critical role in runoff generation. Hughes et al. (2012), demonstrated that runoff ratio $(Q / P)$ was strongly related to groundwater elevation in the catchment, particularly in the riparian zone. As such, the groundwater acts as the catchment "memory", and runoff produced from an average year now produces around $150 \mathrm{~mm}$ less runoff than the same rainfall in the 1970's. In years following droughts runoff coefficient is reduced in subsequent years. In the absence of sustained higher than average rainfall, reduced runoff coefficient is maintained. There have been no years in which annual rainfall was substantially larger than average in the post1974 period in SWA. However, catchment forest clearing experiments provide an analogous example where catchment storage and runoff both increase due to reduced evaporation (Ruprecht and Schofield, 1989; Silberstein et al., 2003). In these examples, clearing increases storage (groundwater lev-
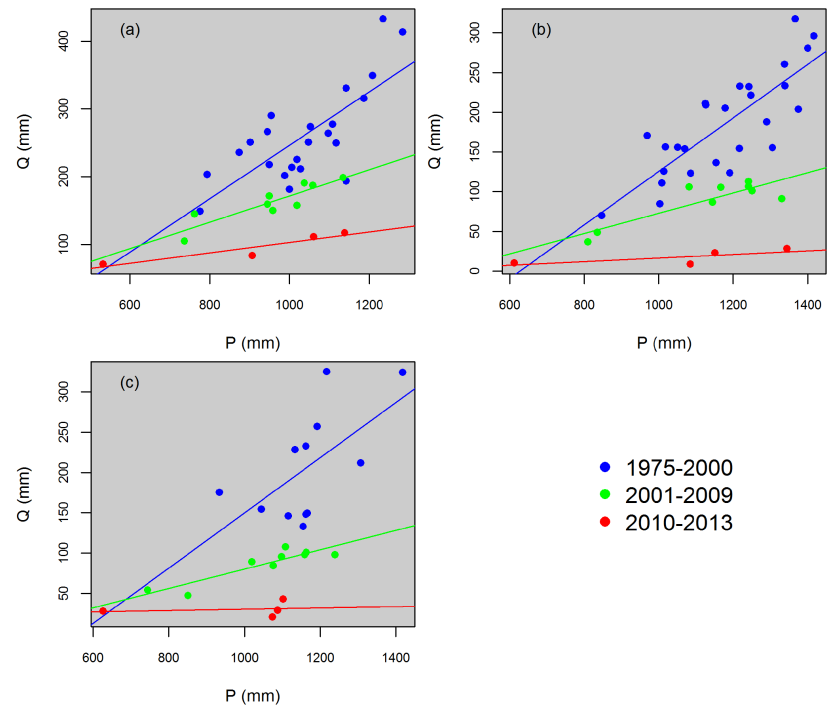

- $1975-2000$

- 2001-2009

- 2010-2013

Figure 1. Annual $Q \sim P$ relationships for three catchments in SWA. Catchments shown are: (a) Waterfall Gully $\left(9 \mathrm{~km}^{2}\right)$, (b) Del Park $\left(2 \mathrm{~km}^{2}\right)$, and (c) Bates $\left(2 \mathrm{~km}^{2}\right)$.

els) resulting in increased runoff. The increase in runoff coefficient coincides with the water table reaching the land surface, often many years after clearing.

\section{Rainfall runoff modelling in environments with long term storage change}

Silberstein et al. (2013) calibrated 5 different RR models: IHACRES, Jakeman et al. (1990); AWBM, Boughton (2004); SMAR, Vaze et al. (2011); SIMHYD, Chiew and Siriwrdena (2005) and Sacramento (Burnash et al., 1973) to 106 gauged catchments in SWA. While goodness of fit (judged by NSE and bias) was excellent in almost all cases, model error was not randomly distributed in time. In many cases error exhibited a trend with negative error (i.e. predictions minus observations) in the early part of the record and positive error in the latter part of the streamflow record. This implies a structural problem in most RR models, but what do all these models do that causes such a problem?

\subsection{Storage dependency}

The influence of antecedent conditions and more specifically catchment storage is the conceptual basis of RR modelling. The soil water accounting modules of most RR models rely on a single or series of interconnected storages that fill and empty with climatic inputs. As storage is the source of both runoff and evaporation, both runoff and evaporation will be larger for given rainfall and potential evaporation inputs. In the "dry" state, a higher proportion of incoming net rainfall will contribute to catchment storage, and less routed to streamflow relative to a "wet" state. 

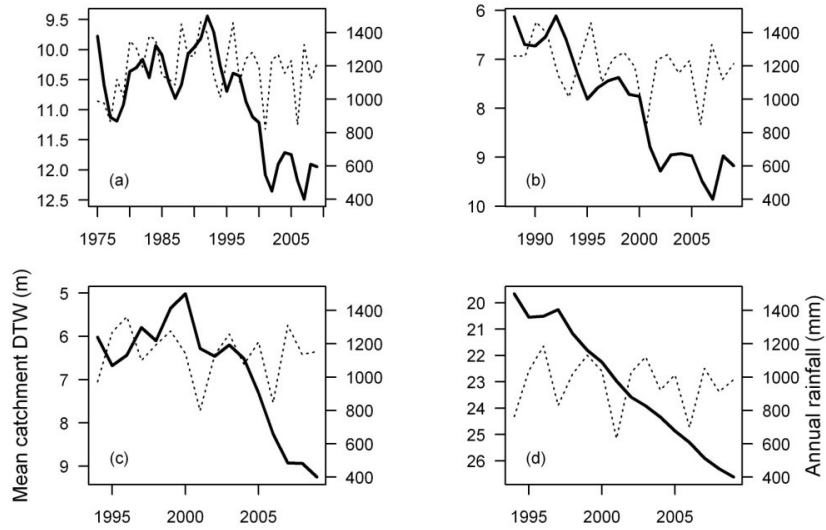

Figure 2. Mean catchment annual depth to groundwater (solid lines) and annual precipitation (dashed lines) for four SWA catchments (from Hughes et al., 2012).

These concepts can take numerous structural forms but all models will behave in a broadly similar way. We constructed a very simple single store model (denoted S1S hereafter) to explore the limitations of this concept with respect to the observed behaviour of catchment storage in SWA. The model uses inputs of net rainfall $\left(P_{\mathrm{n}}\right)$ or net evaporation $\left(E_{\mathrm{n}}\right)$, as primary inputs. Evaporation from the store is calculated as follows;

$E_{\mathrm{s}}=E_{\mathrm{n}} \cdot\left(S / S_{\max }\right)^{p_{1}}$,

where $E_{\mathrm{S}}$ is the daily evaporation $\left(\mathrm{mm} \mathrm{day}^{-1}\right)$ from the store, $S$ is the current store level (mm), $S_{\max }$ is the capacity of the store $(\mathrm{mm})$, and $p_{1}$ is a shape parameter. Input to the store is calculated as follows;

$P_{\mathrm{s}}=P_{\mathrm{n}} \cdot\left(1-\left(S / S_{\max }\right)\right)^{p_{2}}$,

where $P_{\mathrm{S}}$ is the input to the store and $p_{2}$ is a shape parameter. Runoff is calculated as the difference between $P_{\mathrm{n}}$ and $P_{\mathrm{s}}$;

$Q=P_{\mathrm{n}}-P_{\mathrm{s}}$.

A critical observation from the data sets of SWA is that the persistent decline in runoff coefficient is related to a persistent reduction in catchment storage or groundwater levels for catchments (where groundwater remains "connected" to the surface), particularly following droughts (Fig. 2).

We used the S1S model to explore the dynamics of drought induced storage decline and recovery. Data from Bates experimental catchment was used to test the model for its ability to represent annual runoff. A matrix of parameter values was tested $(n>5000)$, using a Monte Carlo approach and assessed for goodness of fit using root mean square error (RMSE). Parameter values were selected from a grid of values that covered what was considered reasonable parameter bounds.

A synthetic input data set was created that consisted of an annual cycle of rainfall and evaporation that was repeated

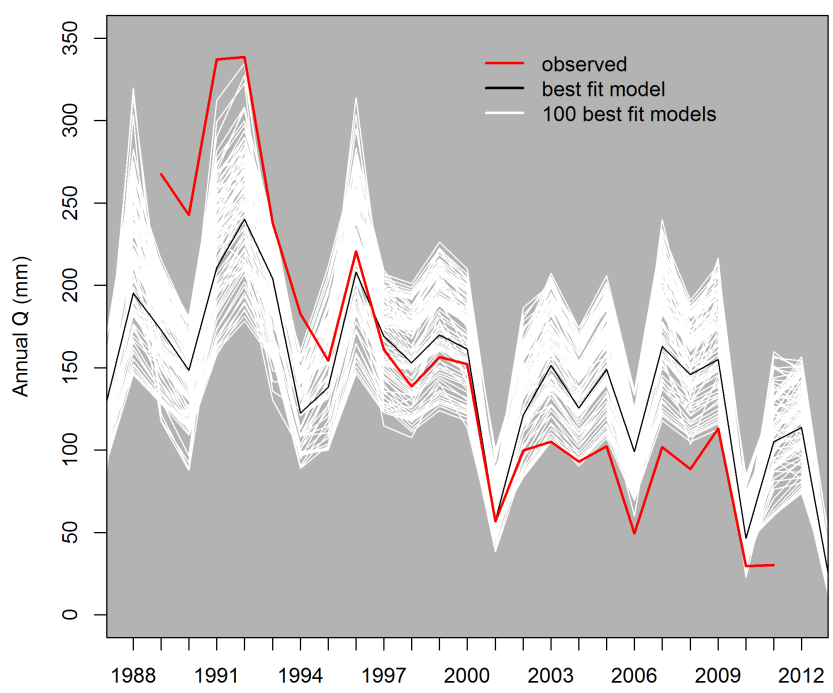

Figure 3. Observed and simulated annual runoff using the S1S model at Bates experimental catchment.

numerous times. These were real data taken from the Bates experimental catchment for the year 2007. Annual $E$ was approximately equal to annual $P$ for these data. Within this time series, one years' rainfall was reduced by $60 \%$ to produce a synthetic drought. $S_{\max }$ was set at 2000 for the investigation and various values of $p_{1}$ and $p_{2}$ were tried.

Calibration of the model showed that it was not possible using the S1S model to adequately represent observed annual runoff (Fig. 3). Figure 3 shows that of the best 100 parameter sets, none were able to reproduce the decline in runoff observed at the catchment. This is not unexpected and gives similar results in the study of Silberstein et al. (2013), where RR models could not represent the decline in runoff across the observation period adequately. For the S1S model, this is related to the inability to represent persistent reductions in model storage following drier years.

The single most important observation is that for any combination of parameters $p_{1}$ and $p_{2}$, post-drought recovery in storage is reasonably rapid, usually within four years, with most of the recovery in the first year after drought (Fig. 4). This is critical, since it shows when model store input is dependent upon the current storage, storage will recover, given "average" conditions. This is in contrast to the situation observed in SWA where there is little to no recovery of groundwater storage (Fig. 2) or runoff (Fig. 1) from years where total rainfall is above $1100 \mathrm{~mm}$ (around average rainfall).

While this is a very simplified structure, similar overarching principles operate in all RR models. So how can a model be restructured to enable more persistent reductions in storage and runoff post-drought? 

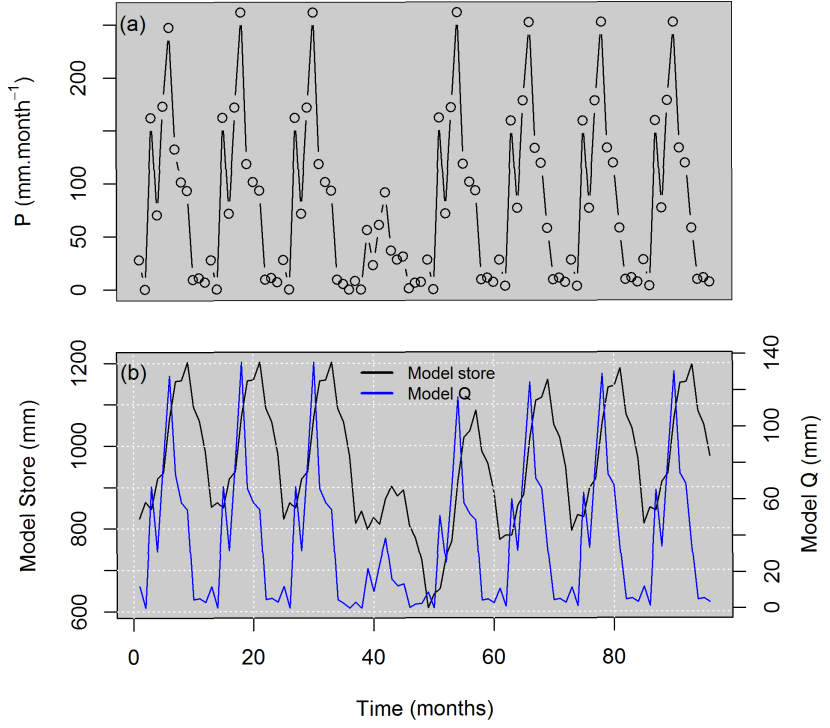

Figure 4. Precipitation input, simulated runoff and model store for the S1S model. Parameters $p_{1}$ and $p_{2}$ are set to 1 for the simulation results presented in this figure.

\section{A proposed structure for long-term storage change}

Most RR models are inspired by a perceptual model of runoff generation processes. For this particular problem, experimental hydrology and our perceived concepts of runoff generation can again assist. In terms of catchment storage, it is typical to consider both unsaturated and groundwater storage explicitly as many RR models do. However, most models consider the maximum storage in each of these reservoirs as fixed throughout any simulation. We know from observations that groundwater storage (water table) will fall during drier periods. This also implies that the unsaturated zone becomes physically larger (given that the regolith volume remains the same), and therefore the maximum storage capacity of the unsaturated zone is dynamic. For a given climatic input a larger unsaturated zone will allow more of any precipitation inputs to be captured, and potentially utilised by vegetation before groundwater recharge is achieved. Given the importance of groundwater-surface water connection in runoff generation, runoff would still be dependent upon this storage while catchment evaporation is dependent upon total unsaturated storage of water.

Runoff can be calculated as a function of groundwater storage $(G)$ and net rainfall;

$Q=f\left(P_{\mathrm{n}}, G\right)$

while evaporation is a function of unsaturated storage;

$E_{\mathrm{s}}=f\left(E_{\mathrm{n}}, U\right)$

and recharge to the unsaturated zone is a function of net precipitation and depth of unfilled unsaturated reservoir $\left(U_{\mathrm{r}}-U\right)$.

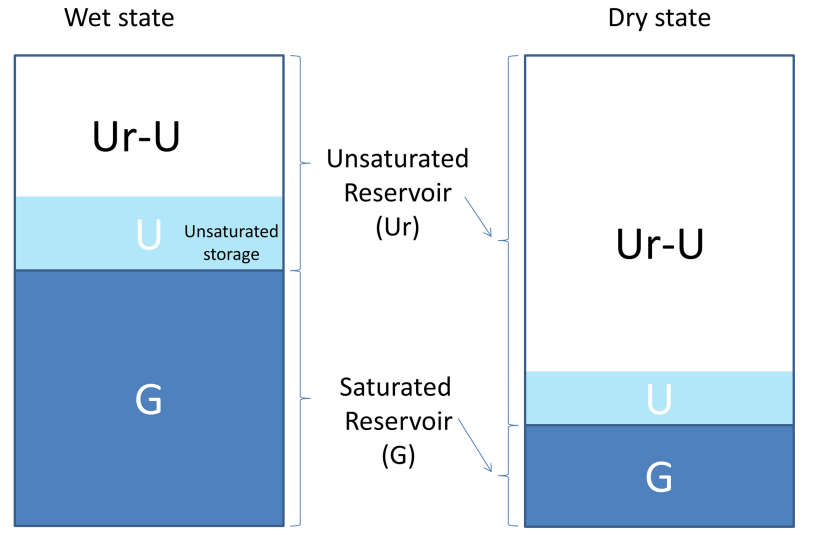

Figure 5. A proposed conceptual model for soil moisture accounting within rainfall-runoff models.

Similarly, movement of water from the unsaturated zone to the saturated storage is a function of $U / U_{\mathrm{r}}$.

A dynamically updated unsaturated reservoir is uncommon in most RR models, with the notable exception of Seibert et al. (2003), who employed dynamically updated unsaturated and saturated stores. This concept was employed to better model groundwater dynamics and isotopic composition of runoff in a humid environment. This is a very different environment to that of SWA. RR model codes in their current format are successfully used in many environments with few problems.

Recently, Westra et al. (2014) explored structural changes to the GR4J model (Perrin et al., 2003). Parameters were introduced that allowed the GR4J production store size to vary as a combination of a linear trend, and annual sinusoid. In addition, an extra parameter that controls the shape of the $P_{\mathrm{s}}=f\left(P_{\mathrm{n}}, S\right)$ relationship was introduced, similar to Hughes et al. (2013). These changes improved goodness of fit and predictive performance. It is possible that the structure proposed here could perform a similar function to the introduced parameters in the Westra et al. (2014) study, by allowing longer term and annual storage changes to be maintained by simulations and reducing trends in model error.

Regolith depth will be an obvious limitation to how far storage (unsaturated and saturated) can vary. SWA features very deep and transmissive regolith that effectively stores the cumulative effects of climate over a longer time span. Shallow regolith is less likely to enable this, and therefore, a dynamically variable unsaturated zone will be of reduced value. Likewise where vegetation is shallow rooted the effective unsaturated zone will be shallow, despite physical potential to be deeper.

A consistently dry climate where potential evaporation is substantially higher than precipitation results in a consistently low storage. Likewise, wet climates create consistently high levels of storage. For both of these situations, the variance in unsaturated storage will be low. It is the variance in 
unsaturated storage that requires a dynamic unsaturated store in a conceptual model. Climate/land-use combinations that vary between water limited and energy limited environments can produce large long-term changes in storage and runoff. When this is evident in combination with the other factors outlined above, non-stationarity in the $Q \sim P$ relationship can result. The proposed model structure may help in those situations.

\section{Conclusions}

Long-term monitoring of experimental catchments in southwestern Australia across a period of climate change has offered new insights into hydrological processes and the effects of groundwater interactions with surface water. Long term changes in groundwater storage have been maintained following droughts leading to new $Q \sim P$ relationships. Rainfall-runoff models that are often used in south-western Australia typically show large trends in error since they are incapable of producing long-term changes in model conceptual storage that is in accordance with observed falls in groundwater storage.

Typically, rainfall-runoff models consist of conceptual moisture stores of static maximum capacity. Testing of a simple RR model with this structure shows that it is impossible to induce long-term storage reduction of the runoff influencing store with a single drought year. In reality as the groundwater table falls or rises, the capacity of the unsaturated zone also changes. An alternative structure is proposed that features a dynamically changing unsaturated store, whose capacity can increase or decrease with prevailing conditions. This structure remains untested but may offer an opportunity to improve model predictive performance in areas where longer term storage changes are likely.

Acknowledgements. Thanks to Ang Yang for assistance with code development for the S1S model.

\section{References}

Bates, B. C., Hope, P., Ryan, B., Smith, I., and Charles, S.: Key findings from the Indian Ocean Climate Initiative and their impact on policy development in Australia, Climatic Change, 89, 339-354, 2008.

Beven, K.: Rainfall-Runoff Modelling: The Primer, 2nd Edn., John Wiley and Sons, Chichester, UK, 2012.

Boughton, W. C.: The Australian Water Balance Model, Environ. Modell. Softw., 19, 943-956, 2004.

Burnash, R. J. C., Ferral, R. L., and McGuire, R. A.: A Generalised Streamflow Simulation System - Conceptual Modelling for Digital Computers, US Department of Commerce, National Weather Service and State of California, Department of Water Resources, US Department of Commerce, National Weather Service, and State of California, Department of Water Resources, Sacramento, 1973.
Chiew, F. H. S. and Siriwrdena, L.: Estimation of SIMHYD parameter values for an application in ungauged catchments, MODSIM 2005, Melbourne, Australia, 2005.

Hughes, J. D., Petrone, K. C., and Silberstein, R. P.: Drought, groundwater storage and stream flow decline in southwestern Australia, Geophys. Res. Lett., 39, L03408, doi:10.1029/2011GL050797, 2012.

Hughes, J. D., Silberstein, R. P., and Grigg, A. H.: Extending rainfall-runoff models for use in environments with longterm catchment storage and forest cover changes, MODSIM 2013, Modelling and Simulation Society of Australia and New Zealand, Adelaide, 2013.

IOCI - Indian Ocean Climate Initiative: Climate vulnerability and change in south west Western Australia, IOCI Panel, Perth, Australia, 2002.

Jakeman, A. J., Littlewood, I. G., and Whitehead, P. G.: Computation of the instantaneous unit hydrograph and identifiable component flows with application to two small upland catchments, J. Hydrol., 117, 275-300, 1990.

Kinal, J. and Stoneman, G. L.: Disconnection of groundwater from surface water causes a fundamental change in hydrology in a forested catchment in south-western Australia, J. Hydrol., 472473, 14-24, 2012.

Klemes, V.: Dilettantism in hydrology; transition or destiny?, Water Resour. Res., 22, 177S-188S, 1986.

Milly, P. C. D., Betancourt, J., Falkenmark, M., Hirsch, R., Kundzewicz, Z. W., Lettenmaier, P., and Stouffer, R. J.: Stationarity is dead: Whither water management?, Science, 319, 573574, doi:10.1126/science.1151915, 2008.

Perrin, C., Michael, C., and Andreassian, V.: Improvement of a parsimonious model for streamflow simulations, J. Hydrol., 279, 275-289, 2003.

Petrone, K. C., Hughes, J. D., Van Niel, T. G., and Silberstein, R. P.: Streamflow decline in southwestern Australia, 1950-2008, Geophys. Res. Lett., 37, 11401, doi:10.1029/2010GL043102R, 2010.

Ruprecht, J. K. and Schofield, N. J.: Analysis of streamflow generation following deforestation in southwest Western Australia, J. Hydrol., 105, 1-17, 1989.

Ruprecht, J. K. and Schofield, N. J.: Infiltration characteristics of a complex lateritic soil profile, Hydrol. Process., 7, 87-97, 1993.

Seibert, J., Rodhe, A., and Bishop, K.: Simulating interactions between saturated and unsaturated storage in a conceptual runoff model, Hydrol. Process., 17, 379-390, 2003.

Silberstein, R. P.: Hydrological models are so good, do we still need data?, Environ. Modell. Softw., 21, 1340-1352, 2006.

Silberstein, R. P., Adhitya, A., and Dabrowski, C.: Changes in flood flows, saturated area and salinity associated with forest clearing for agriculture, Tech. Rep. 03/1, Co-operative Centre for Catchment Hydrology, Melbourne, 2003.

Silberstein, R. P., Aryal, S. K., Braccia, M., and Durrant, J.: Rainfall-runoff model performance suggests a change in flow regime and possible lack of catchment resilience, MODSIM 2013, Modelling and Simulation Society of Australia and New Zealand, Adelaide, 2013.

Stokes, R. A.: Stream Water and Chloride Generation in a Small Forested Catchment in South Western Australia, Water Authority of Western Australia, Perth, Australia, Report No. WH7, 176 pp., 1985. 
Stokes, R. A. and Loh, I. C.: Streamflow and solute characteristics of a forested and deforested catchment pair in southwestern Australia, in: Proceedings of the First national Symposium on Forest Hydrology, Melbourne, 11-13 May 1982, edited by: O'Loughlin, E. M. and Bren, L. J., The Institution of Engineers Australia, National Conference Publication 82/6, Canberra, Australia, 60-66, 1982.

Turner, J. V., Macpherson, D. K., and Stokes, R. A.: The mechanisms of catchment flow processes using natural variations in deuterium and oxygen-18, J. Hydrol., 94, 143-162, 1987.
Vaze, J., Post, D. A., Chiew, F. H. S., Perraud, J.-M., Teng, J., and Viney, N.: Conceptual rainfall-runoff model performance with different spatial rainfall inputs, J. Hydrometeorol., 12, 11001112, doi:10.1175/2011JHM1340.1, 2011.

Westra, S., Theyer, M., Leonard, M., Kavetski, D., and Lambert, M.: A strategy for diagnosing and interpreting hydrological model nonstationarity, Water Resour. Res., 50, 5090-5113, doi:10.1002/2013WR014719, 2014.

Williamson, D. R., Stokes, R. A., and Ruprecht, J. K.: Response of input and output of water and chloride to clearing for agriculture, J. Hydrol., 94, 1-28, 1987. 